\title{
DOCEAMUS
}

doceamus...let us teach

\section{Mathematics in the Yates Program at Illinois College}

Jeremy F. Alm and Andrew B. Jones

Illinois College is a small liberal arts college in Jacksonville, Illinois. We serve just under one thousand undergraduate students, more than half of whom are first generation or low income. We are a test-optional institution with an average ACT mathematics subscore of 22. The ACT benchmarks indicate that 45 percent of our students should not expect to have a successful outcome (C or better) in their first mathematics course at Illinois College. We also enroll a number of students from underresourced high schools that are unable to provide either the breadth or depth of mathematics instruction to prepare students for the rigor of the college classroom. Many of our students begin their first year of college having completed only three years of mathematics in high school, often ending their coursework with Algebra II.

To address the underpreparedness of our entering students, Illinois College instituted the Yates Summer Bridge Program for first-generation college students. For two weeks prior to the start of classes, eighteen first-year first-generation students participate in a living/learning community, the purpose of which is to introduce participants to the academic rigor and expectations of Illinois

Jeremy F. Alm is associate professor of mathematics at Illinois College. His email address is a $1 \mathrm{~m}$. academic@gmai1. com.

Andrew B. Jones is dean of student success at Illinois College. His email address is andrew. jones@mai 1 . ic. edu.

Members of the Editorial Board for Doceamus are: David Bressoud, Roger Howe, Karen King, William McCallum, and Mark Saul.

For permission to reprint this article, please contact: reprint-permission@ams .org.

DOI: http://dx.doi.org/10.1090/noti1298
College. We focus primarily on mathematics and writing instruction, as we know that deficits in these areas are the primary academic obstacles to success.

Students enrolled in the Yates Program have two hours of mathematics instruction and one hour of mathematics lab every day of the program, for approximately twenty-five total hours of engagement with mathematics. Yates Fellows also generate several drafts of their first college writing assignment during their writing course and participate in a variety of service and team-building activities designed to connect them to one another, to their faculty leaders, and to the institution at large. The crux of the program, however, is the academic preparation and success strategy intervention that will lay the foundation for their success as college students.

While summer bridge programs are increasingly common, our approach to academic skill development-particularly as it relates to mathematics instruction-is successful, based on professional practice, and easily replicable. Below, we discuss the details of this approach to mathematics in the Yates Program (and, more generally, in college algebra courses), why this unconventional approach is necessary, and give a priori reasons to believe it should be more successful than the standard approach. ${ }^{1}$

\footnotetext{
${ }^{1}$ The a priori case that students are better off learning better mathematics is clear enough. The a posteriori case that student learning in the classroom is actually improved is more complicated (but anecdotal evidence and our observations certainly support it). In particular, small sample sizes are a major issue. We are currently working on constructing a multiyear study over several cohorts to measure the practical effectiveness of the approach described here.
} 


\section{Pathology}

In "A revolution in mathematics? What really happened a century ago and why it matters today," Quinn [1] details the profound changes that took place in roughly 1890-1930, through which mathematics took its modern form, characterized by precision, rigor, and free use of proof by contradiction. The importance and utility of modern definitions would be difficult to overstate; a good definition is a tool that is designed to be used. Yet, despite the profound successes of mathematics in the twentieth century, the school mathematics curriculum in the United States has not adopted and integrated the changes that made this success possible. As has been thoroughly and depressingly documented by Hung-Hsi Wu, one rarely finds in the school curriculum (especially K-8) a definition from which one would be able to make deductions or prove things. A particularly glaring omission is the lack of definition of a fraction. ${ }^{2,3}$ Since students are not told what a fraction is, only what it is like (like a piece of pizza, etc.), when asked to reason about fractions they are forced to rely on rote mechanics.

If we want students to be able to actually use fractions, then core experience points a way: use a precise definition that looks obscure at first but that can be internalized by working with it and that is far more effective once it is learned. [1]

It may be that these curricular problems have consequences for faculty as well; the dislike of teaching courses such as college algebra among mathematics faculty is nearly universal. A reason frequently given is that such courses are too "low-level." This reason seems to be inadequate to explain the depth and ubiquity of the hatred; it might be that it is the lack of adherence to the standards of the discipline that is the problem. (The first author's cursory survey of college algebra textbooks found that most suffered from the insufficiencies of the high school textbooks described by $\mathrm{Wu}$ in [2].) After all, Wu [4] says, "There is no trivial mathematics, only trivial mathematical exposition." The thrust of our work in remedial mathematics at Illinois College is to give rational arithmetic, leading up through elementary algebra, a nontrivial exposition for our students.

\footnotetext{
${ }^{2}$ One finds mention of this omission in much of Wu's writing on education; a good place to start is [7].

${ }^{3}$ While this column was under review, an editor pointed out that over forty states have now adopted curricula that include proper definitions of "fraction." This is an encouraging sign, yet for the next ten years we will still have to deal with the fact that so many of the college students in our classes have learned algebra with foundation in arithmetic that was shaky at best.
}

\section{Mathematics at Illinois College}

In the Yates Program, we begin with Wu's definition of a fraction as a certain kind of point on the number line. (See [5], [6].) Addition of fractions is defined geometrically using concatenation of line segments, and we prove that the usual addition formula $\frac{a}{b}+\frac{c}{d}=\frac{a d+b c}{b d}$ is correct. We proceed quickly-after all, we have only two weeks-through fraction arithmetic, decimals, percentages, and linear equations in a single unknown. We pay careful attention throughout to the fact that everything we do is in service to the goal of achieving facility with algebra. A point on which $\mathrm{Wu}$ is quite persuasive (see [3]) is that if fractions were taught in a way that was both rich and consistent with modern practice, then fraction arithmetic would provide a smooth path to algebra. We testify that this claim bears out in actual practice. Many Yates students take the first author's college algebra course in the fall semester, of which the first three weeks are more or less a repeat of the Yates Program, and these students (along with other college algebra students) who are willing to change their thinking are able to make sense of the more abstract manipulations (algebra) in virtue of the fact that we had made coherent the concrete (arithmetic). The initial investment in establishing a solid grounding in rational arithmetic pays dividends, though it does require an investment of time; one might say that while the standard college algebra course moves at constant velocity, the course described here moves at constant acceleration.

One of the best illustrations available to the students of the power of definition-as-tool is the definition of percentages:

Definition. Let $N$ be a fraction. Then $N$ percent is defined to be the (complex) fraction $\frac{N}{100}$.

Many people reason with percentages using intuitive notions, but intuition is not that hard to foil, as, for instance, with the following question:

What percent of $\frac{7}{2}$ percent is 19 percent ${ }^{4}$

This question strikes most people as confusing, but it lends itself perfectly well to literal translation using the definitions of percentage and of fraction multiplication: ${ }^{5}$

Let $N$ be the unknown fraction. Then

$$
\frac{N}{100} \times \frac{7 / 2}{100}=\frac{19}{100} \text {. }
$$

\footnotetext{
${ }^{4}$ Questions such as this-those that expose the dysfunctionality of the methods most students learn in high school-are essential for helping the students change their point of view. If given only "standard" questions, students may be able to get along by leaning on their old crutches. Wu's materials are full of such stultifying questions.

${ }^{5}$ Wu's definition [5], [6] of fraction multiplication, although slightly complicated, is nonetheless intuitive and is clearly modeled on the common use of "of", as in, "Give me 2/3 of that submarine sandwich."
} 


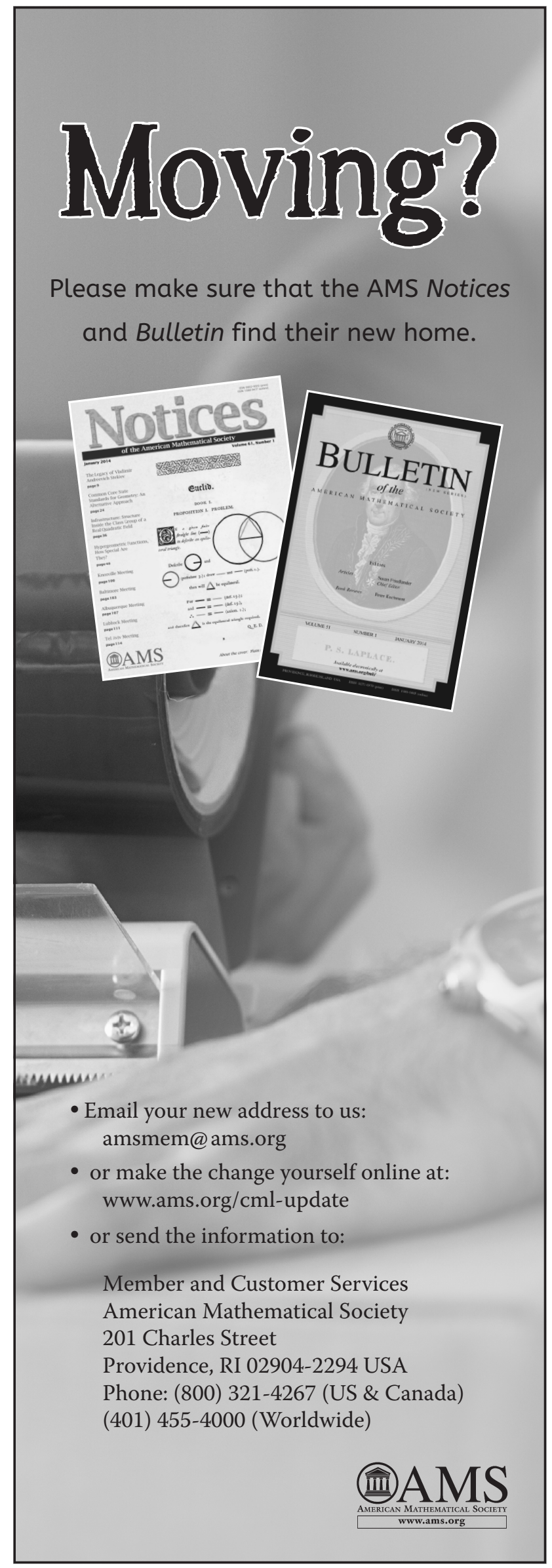

Quinn and $\mathrm{Wu}$ both argue for the need for updates to the K-12 curriculum to take advantage of the high functionality of the modern methodology in mathematics. Here we have presented some evidence that college students in high school-level courses can benefit as well, especially those who are disadvantaged and at the greatest risk for attrition. A side benefit may be that faculty would find such courses less arduous-even enjoyable-to teach. The first author enjoys teaching college algebra, as he enjoys mathematical research; both efforts are part of a common project to produce mathematics that is correct, coherent, and beautiful, and to help others do the same.

\section{References}

[1] FRANK QUINN, A revolution in mathematics? What really happened a century ago and why it matters today, Notices Amer. Math. Soc. 59 (2012), no. 1, 31-37.

[2] M. SAUL, ed., Response to the Elizabeth Green article, Notices Amer. Math. Soc. 62 (2014), no. 5, 508-514.

[3] H. WU, From arithmetic to algebra (2009), https:// math . berkeley.edu/ wu/C57Eugene_3.pdf.

[4] _ What is school mathematics? (2010), https:// math. berkeley.edu/ wu/Lisbon2010_3.pdf.

[5] _ Understanding Numbers in Elementary School Mathematics, American Mathematical Society, 2011.

[6] _ What's sophisticated about elementary mathematics? American Educator (Fall 2009), www.aft. org/sites/default/files/periodicals/wu_0.pdf

[7] , How to prepare students for algebra, American Educator (Summer 2001), www.aft.org/sites/ default/files/periodicals/algebra.pdf. 